\title{
Systematic Layout Planning for Germinated Brown Rice Mill under GMP and ISO22000:2005 requirements
}

\author{
Natthapong Nanthasamroeng ${ }^{1}$,Kanokwan Supakdee ${ }^{2}$,Tasapong Klaewthanong ${ }^{3}$, \\ Pawinyada Boonrom ${ }^{4}$, Chet Srimaitree ${ }^{5}$ and Peerasak Kittisriworapan ${ }^{6}$ \\ ${ }^{1}$ Lecturer, Graduate School of Engineering Technology, Faculty of Industrial Technology, \\ Ubon Ratchathani Rajabhat University, Ubon Ratchathani, Thailand \\ 2,3,4,5 Lecturers, Department of Industrial Management Technology, Faculty of Industrial Technology \\ Ubon Ratchathani Rajabhat University, Ubon Ratchathani, Thailand \\ ${ }^{6}$ Assistant Professor, Department of Industrial Management Technology, Faculty of Industrial Technology \\ Ubon Ratchathani Rajabhat University, Ubon Ratchathani, Thailand
}

\begin{abstract}
This research aimed to study the effect of international standard for food safety to facility layout planning. Systematic layout planning was the procedure which be modified by integrated GMP and ISO22000 requirement into the initial phase of SLP. The result revealed that the integrated requirements help ensuring the safety and quality of food production process. In addition, three alternative layouts were developed and evaluated by using the materials handling distance as a criterion. The improved layouts could reduce the excessive transportation $76.66 \%$ to $81.21 \%$ and the selected layout can reduce distance from 47 meters to 8.83 meters.
\end{abstract}

Keywords — Systematic Layout Planning, Facility Planning, GMP, ISO22000, Rice Mill

\section{INTRODUCTION}

Facility layout planning is an important activity for every manufacturing. A bad facility layout leads to excessive cost and ineffective production processes. So, an appropriate plant layout planning and design contributed to productivity of the factory and shorter lead time.[1]

In the food industry, a lot of requirements were forced the factory including GMP and HACCP. Some of those requirements had effects to facilities layout. Donk and Gaalman [2] were studied the food safety requirements and offered an approach that enables hygienic layout design of a food-processing plant that is particularly useful in production engineering and design for food processing companies. However, there is a little published papers concern about food hygienic in germinated brown rice mill which had specific processes. Therefore, this paper studied about facility planning and the effects of GMP and ISO22000 requirements on systematic plant layout for germinated brown rice mill in community enterprise.

\section{LITERATURE REVIEW}

Systematic layout planning or SLP is the facility layout design method which developed by Muther [3] in 1976. SLP methodology consisted of 11 steps including initial data investigation or PQRST analysis, flow analysis, activities relationship analysis, determining relationship diagram, space requirements calculation, space adjustment, determining space relationship diagram, modifying constraints, practical limitation, developing layout alternatives, and layout evaluation[4]. There are many academic papers studied the application of SLP in various industries. Kaewchua and Kiatnukul [5] used SLP to improve metal box plant in Thailand. The result of improvement could decrease material handling distance from 191.51 meters to 128.33 meter or 34\% decreasing. Somsook et al.[6] had also applied SLP to wood furniture factory and reduced material handling distance $60.35 \%$, material handling time $56.30 \%$ and production capacity increase $34.26 \%$.

Good manufacturing practice or GMP was developed by CODEX, international food standard established by Food and Agriculture Organization of United Nation or FAO and World Health Organization or WHO, and was adopted by many countries worldwide. GMP is a manufacture and testing practice which helps to ensure quality and safety of food and drug [7]. Many research papers studied about GMP in food manufacturing. Matyjek et al. [8] surveyed the situation of implementation Critical Control Point (HACCP), Good Manufacture Practice (GMP) and Good Hygiene Practice (GHP) in food manufacturing plants. The survey revealed that $91 \%$ of the surveyed plants are familiar with GHP rules and $95 \%$ with HACCP. Amoa-Awua et al [9] studied about the effect of applying GMP and HACCP to traditional food processing at a semi-commercial kenkey production plant in Ghana. Their result showed that application of GMP and HACCP was effective as a quality management system for assuring the safety of kenkey in the traditional processing of maize into kenkey. 
ISO22000 is an international standard for food safety management system developed by International Organization for Standardization. The ISO 22000 standard specified the requirements for a food safety management system that involves four element including interactive communication, system management, prerequisite programs and HACCP principles. ISO 22000 had been aligned with ISO 9001 in order to enhance the compatibility of the two standards and also integrated the principles of the HACCP system and application steps developed by the Codex Alimentarius Commission.[10]

\section{METHODOLOGY}

Methodology of germinated brown rice mill's facility planning followed Muther's SLP procedure. However, GMP and ISO22000 requirements were considered in the PQRST and relationship analysis session. Therefore, the modified SLP procedure was shown in Fig. 1.

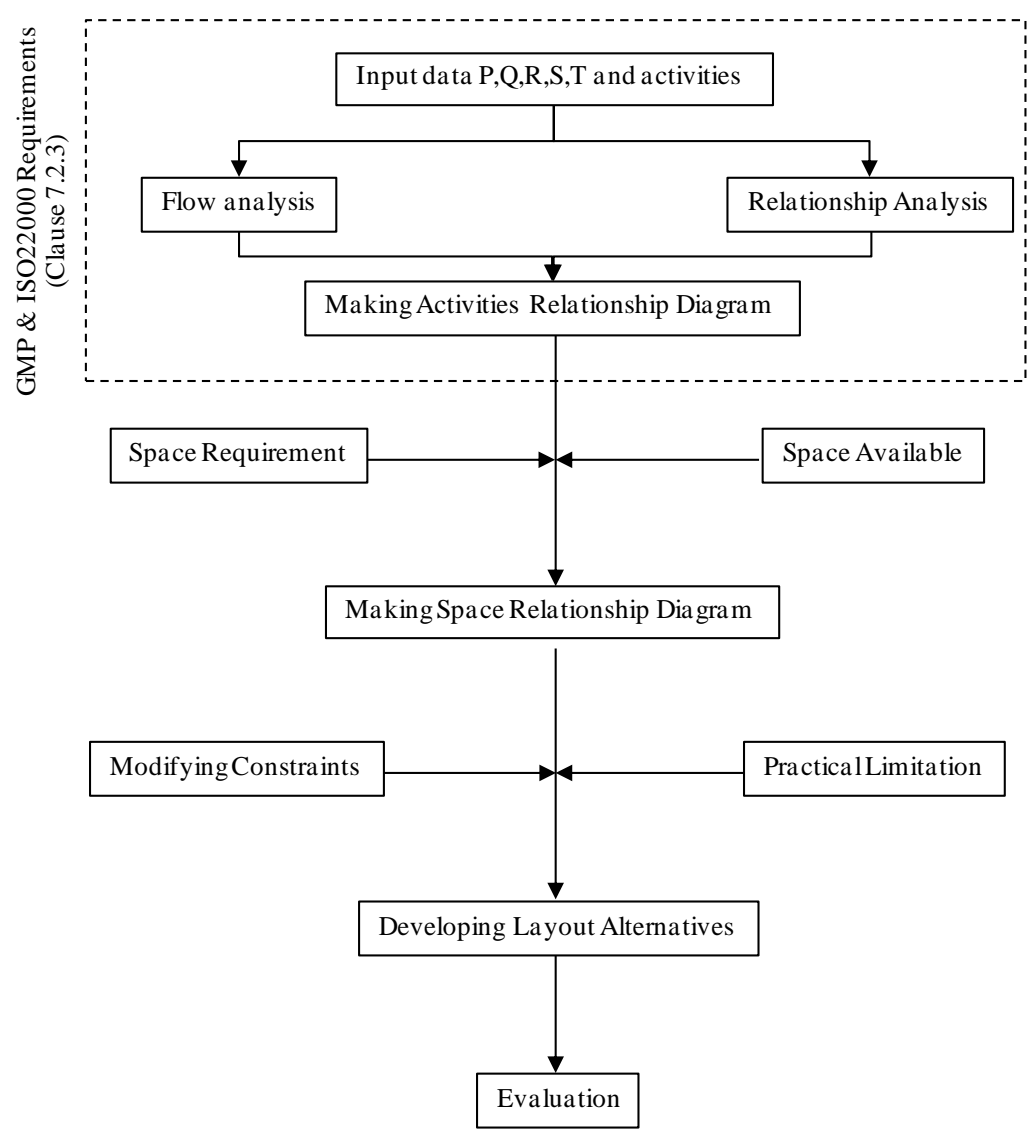

Figure 1 Systematic Layout Planning with GMP and ISO22000 requirements.

\section{RESULT AND DISCUSSION}

4.1 Input data $P, Q, R, S, T$ and activities

Input data was collected by interview, investigation and field survey. All necessary data was described in table 1.

Table 1 Data PQRST

\begin{tabular}{|c|l|l|}
\hline Data & \multicolumn{1}{|c|}{ Details } & \multicolumn{1}{|c|}{ Remarks } \\
\hline Product (P) & Germinated brown rice & \\
\hline Quantity (Q) & 100 kilograms per day & \\
\hline Routing (R) & See Fig.1 & $\begin{array}{l}\text { GMP and ISO22000 required dressing } \\
\text { room before enter into production } \\
\text { process. }\end{array}$ \\
\hline $\begin{array}{c}\text { Support Service } \\
(\mathrm{S})\end{array}$ & Dressing room & $\begin{array}{l}\text { Average demand 3,000 kilogram per } \\
\text { month }\end{array}$ \\
\hline Time (T) & \\
\hline
\end{tabular}




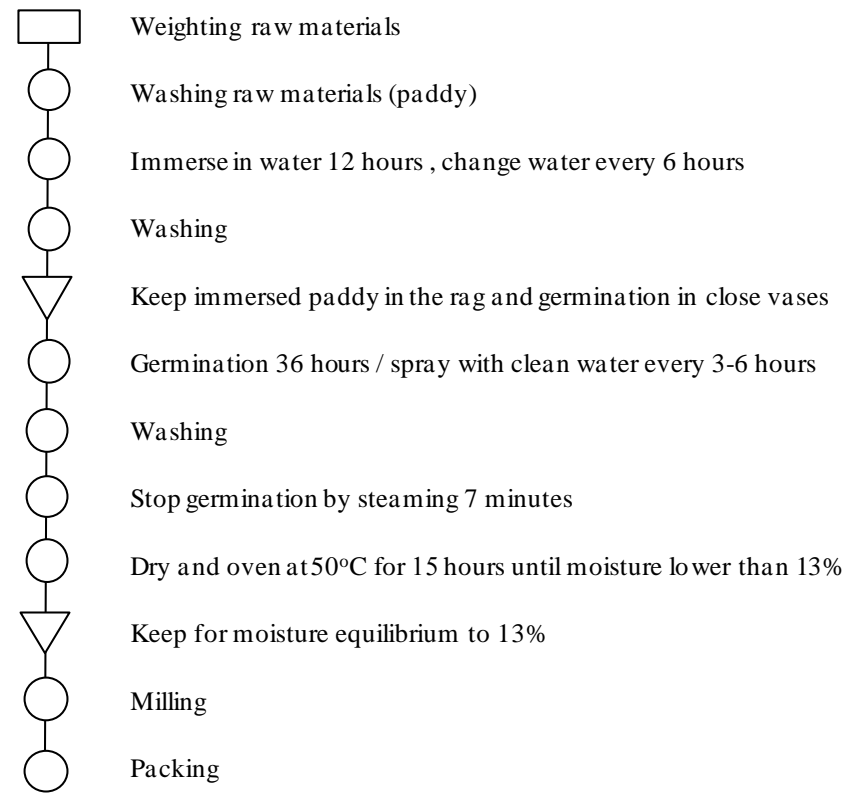

Figure 1 Production process of germinated brown rice.

\subsection{Flow analysis}

Flow process chart was selected to analyze the flow of material from the beginning to the end of process. The flow process chart of germinated brown rice production was shown in Table 2.

The material flow of germinated brown rice production could be categorized to five main activities including operation, transportation, inspection, delay and storage. There were 5 operation activities, 6 transportation activities, 1 inspection activity, and 1 storage activities. The distance of material handling in the traditional facility layout was 47 meters. There was excessive transportation between rice milling process and drying process because of separation of the machine. 
Table 2 Flow process chart for flow analysis

\begin{tabular}{|c|c|c|c|c|c|c|}
\hline \multirow{2}{*}{\multicolumn{3}{|c|}{$\begin{array}{l}\text { CHART NO. } 1 \text { SHEET NO.1 } \\
\text { ACTIVITY: TRADITIONAL GERMINATED BROWN RICE } \\
\text { PRODUCTION }\end{array}$}} & \multicolumn{4}{|c|}{ SUMMARY } \\
\hline & & & & PRESENT & PROPOSE & SAVING \\
\hline \multicolumn{3}{|c|}{ LOCATION: UBON RATCHATHANI, THAILAND } & OPERATION & 5 & - & - \\
\hline \multicolumn{3}{|c|}{ PREPARED DATE: 16 JANUARY 2012} & TRANSPORTATION & 6 & - & - \\
\hline \multicolumn{3}{|c|}{ APPROVED DATE: 16 JANUARY 2012} & INSPECTION & 1 & - & - \\
\hline \multirow{3}{*}{$\begin{array}{l}\text { OPERATOR: } \\
\text { SUPERVISOR: }\end{array}$} & \multirow{3}{*}{\multicolumn{2}{|c|}{$\begin{array}{l}\text { KANOKWAN SUPAKDEE } \\
\text { PAWINYADA BOONROM } \\
\text { CHET SRIMAITREE } \\
\text { ASST.PROF.PEERASAK S. } \\
\text { NATTHAPONG N. }\end{array}$}} & DELAY & 0 & - & - \\
\hline & & & STORAGE & 1 & - & - \\
\hline & & & DISTANCE (METER) & 47 & - & - \\
\hline $\begin{array}{l}\text { DISTANCE } \\
(\mathrm{m})\end{array}$ & $\begin{array}{l}\text { TIME } \\
\text { (sec.) }\end{array}$ & \multicolumn{2}{|c|}{ SYMBOL } & \multicolumn{3}{|c|}{ DESCRIPTION } \\
\hline- & N/A & & & \multicolumn{3}{|c|}{$\begin{array}{l}\text { Raw materials receiving } \\
\text { (after germination process) }\end{array}$} \\
\hline 10 & N/A & & & \multicolumn{3}{|c|}{ Move to drying process } \\
\hline- & N/A & & & \multicolumn{3}{|c|}{ Drying process } \\
\hline 14 & N/A & & & \multicolumn{3}{|c|}{ Move to rice milling process } \\
\hline- & N/A & & & \multicolumn{3}{|c|}{ Rice milling process } \\
\hline 1 & N/A & & & \multicolumn{3}{|c|}{ Move to packing area } \\
\hline- & N/A & & & \multicolumn{3}{|c|}{ Packing rice to plastic bag } \\
\hline 3 & N/A & & & \multicolumn{3}{|c|}{ Move to scale } \\
\hline- & N/A & & & \multicolumn{3}{|c|}{ Weight the finish product } \\
\hline 16 & N/A & & & \multicolumn{3}{|c|}{ Move to packing station 2} \\
\hline - & N/A & & & \multicolumn{3}{|c|}{$\begin{array}{l}\text { Packing station } 2 \\
\text { (wrapping with brand's packaging) }\end{array}$} \\
\hline 3 & N/A & & & \multicolumn{3}{|c|}{ Move to storage area } \\
\hline & N/A & & & \multicolumn{3}{|l|}{ Storage } \\
\hline 47 & N/A & 56 & & \multicolumn{3}{|l|}{ Total } \\
\hline
\end{tabular}

\subsection{Relationship analysis and activity relation diagram}

Activities in the germinated brown rice production process were arranged in 12 activities including material receiving, drying, rice milling, packing, weighting after pack, chemical storage, toilet, washing area, equipment storage, and dressing room. The arrangement of activities was based on GMP and ISO22000 requirements. All activities were analyzed their relationship by using activity relationship diagram as shown in Fig.3

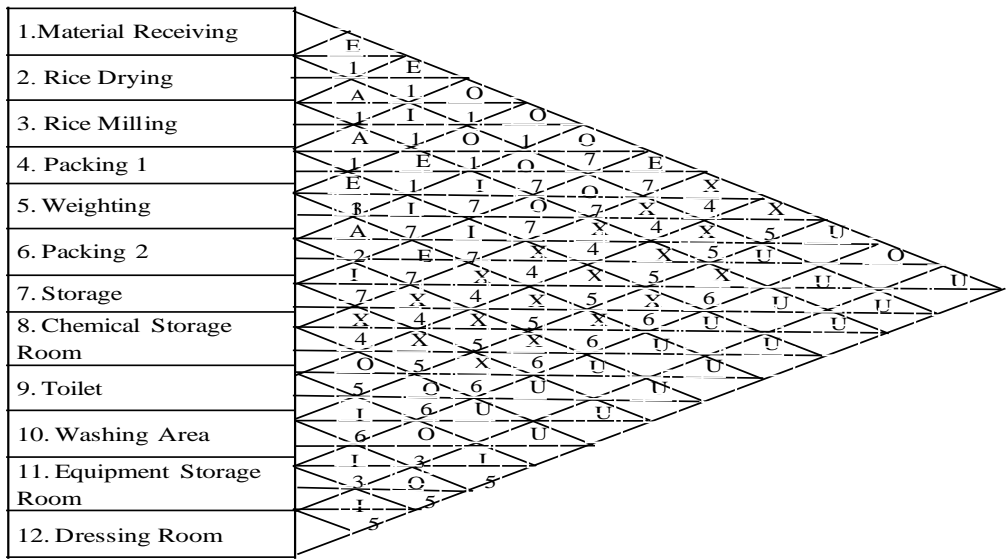




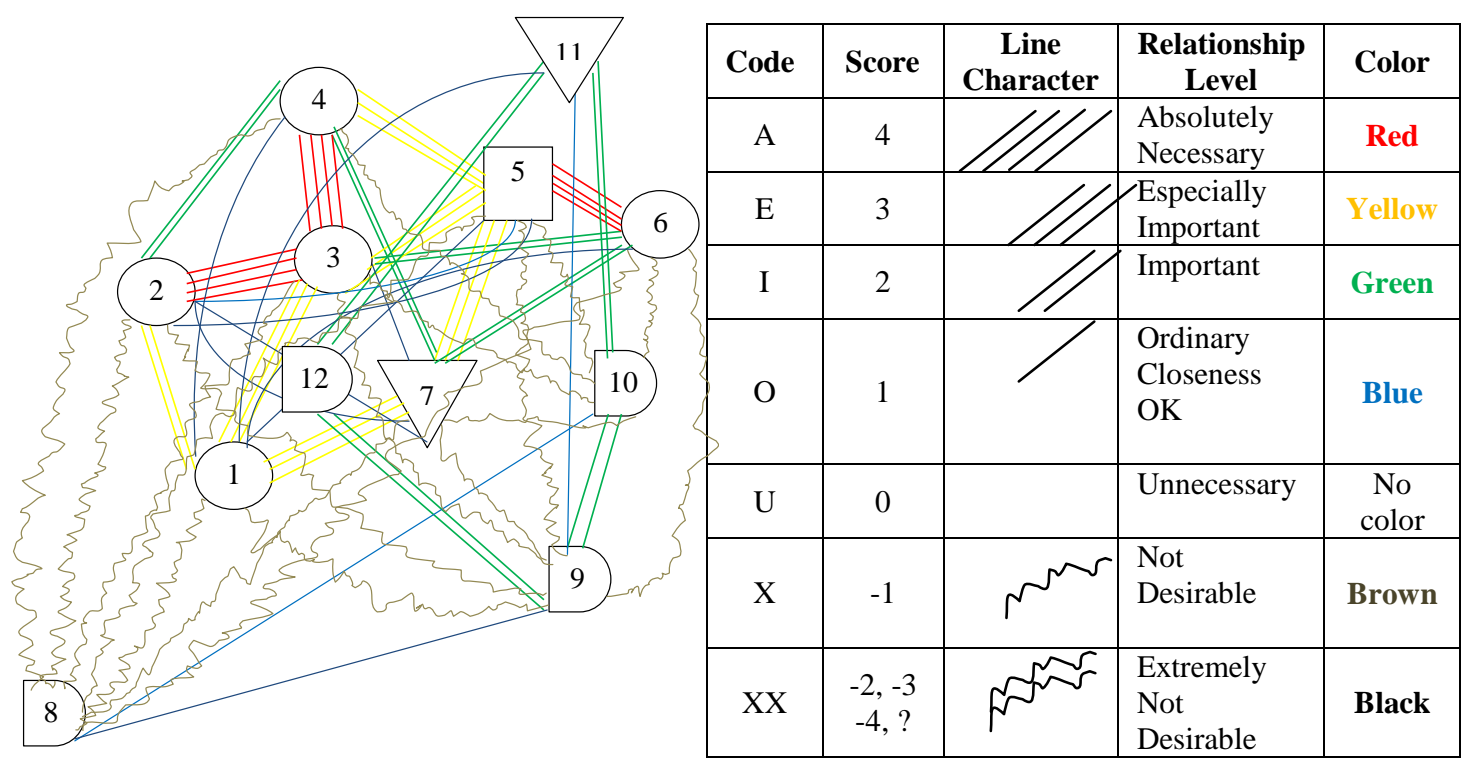

Figure 3 Relationship diagram for germinated brown rice production.

Relationship diagram showed that chemical storage room (No.8) was extremely undesirable from other activities except toilet (No.9) and washing area (No.10). Similarly, toilet and washing areas were prohibited from production and packing process. This result revealed that a consideration of GMP \& ISO22000 requirements in SLP procedure can help to ensure the safety and hygiene of food production.

\subsection{Layout alternatives}

After the consideration about space and other constraints we established three alternatives of germinated brown rice mill. The layout and flow diagram of each alternative were shown in Fig.4.
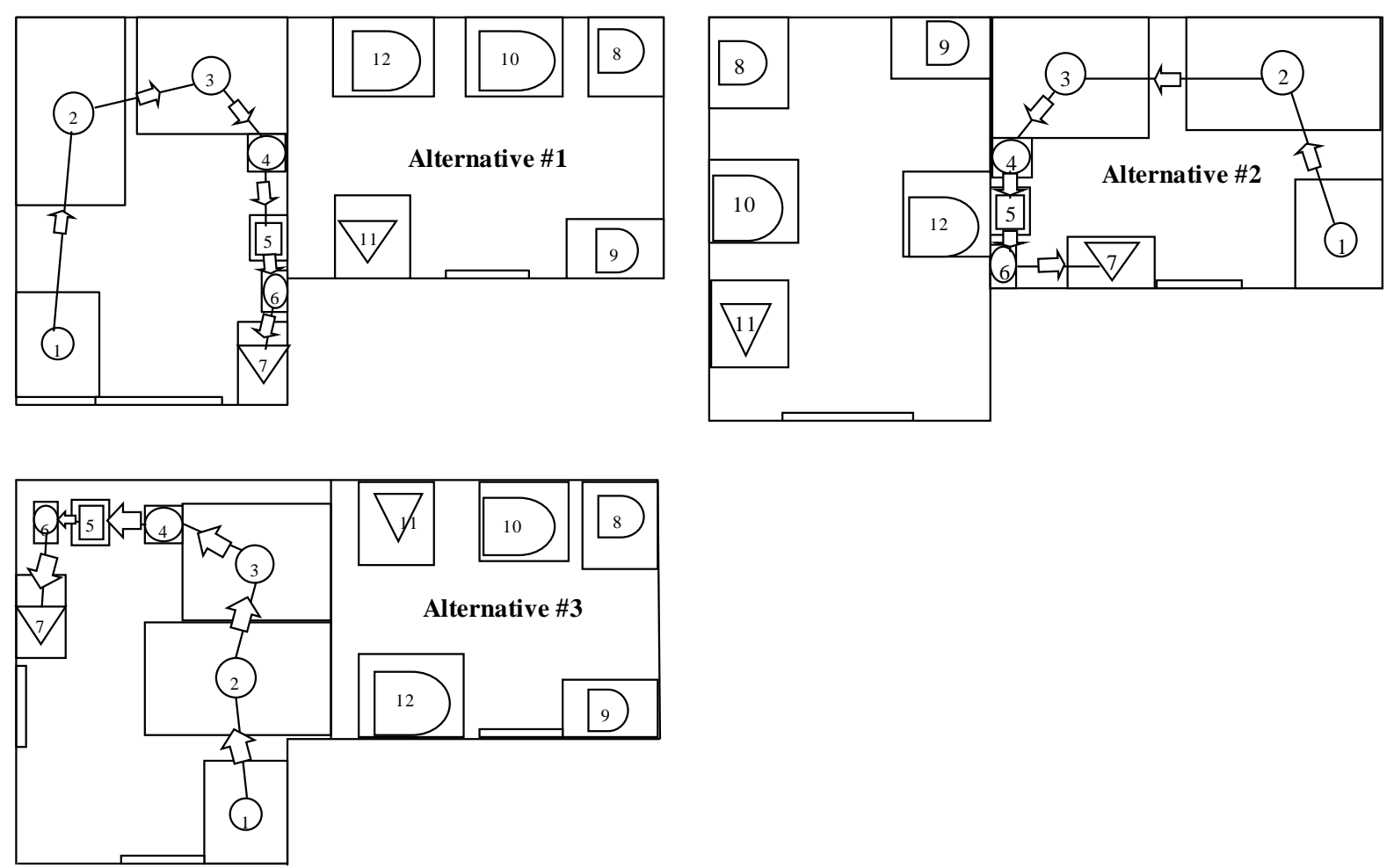

Figure 4 The alternative facility layout for germinate brown rice mill. 
In an alternative layout number 1, all machines in production process were moved into the single room on the left hand side. This improvement could reduce the excessive transportation distance from 47 meters to 10.83 meters. The alternative layout number 2 was improved in the same manner, production processes were grouped and arrange in the single room. However, in an alternative layout number 2, space between each machine was different. Therefore, distance of material handling was reduced to 10.97 meters. The last alternative layout, number 3 , was modified the structure of factory building to allow minimization of gap between drying machine and rice milling machine. This alternative layout could reduce material handling distance to 8.83 meters.

\subsection{Evaluation}

In this paper, an evaluation criterion for selecting the appropriate facility layout for germinated brown rice was material handling distance. So, the evaluation result was shown in table 3.

Table 3 Evaluation result

\begin{tabular}{|l|c|c|c|c|}
\hline \multicolumn{1}{|c|}{ Facility Layout } & Present & Alternative\#1 & Alternative\#2 & Alternative\#3 \\
\hline Material handling distance $(\mathrm{m})$ & 47.00 & 10.83 & 10.97 & 8.83 \\
\hline \% Reduction & & $76.96 \%$ & $76.66 \%$ & $81.21 \%$ \\
\hline
\end{tabular}

\section{CONCLUSION}

This research was studied about systematic layout planning for germinated brown rice mill in community enterprise under GMP and ISO22000 requirements. Three facilities layout were designed by using SLP procedure with food safety requirement consideration. The evaluation criterion in this paper was material handling distance. Therefore, the alternative layout number 3 was an appropriate facility layout which could reduce material handling distance from 47 meters to 8.83 meters or $81.21 \%$ reduction.

\section{ACKNOWLEDGEMENTS}

This research was funded by NRCT and Ubon Ratchathani Rajabhat University from annual government budget of fiscal year 2012 .

\section{REFERENCES}

[1] Giuseppe Aiello, Giada La Scalia, and Mario Enea, A multi objective genetic algorithm for the facility layout problem based upon slicing structure encoding ,Expert Systems with Applications, 39(12), 2012, 10352-10358.

[2] D.P. Van Donk, G. Gaalman, Food Safety and Hygiene: Systematic Layout Planning of Food Processes, Chemical Engineering Research and Design, 82(11), 2004, 1485-1493.

[3] Muther, R., Systematic Layout Planning (Industrial Education Institute, Boston, 1961).

[4] Te-King Chien, An empirical study of facility layout using a modified SLP procedure, Journal of Manufacturing Technology Management, 15(6), 455 - 465.

[5] Kaewchua, P. and Kiatnukul, W., Improvement of factory layout: A case study in cooling tower factory, Proc. IE Network 2011 Conf., Pattaya, Chonburi, 2011, 336-342.

[6] Somsuk, N. et al., A study and improvement of plant layout approach to improve productivity, Proc. IE Network 2007 Conf., Phuket, 2007, 388-392.

[7] http://www.codexalimentarius.org/about-codex/en/

[8] E. Konecka-Matyjek, H. Turlejska, U. Pelzner, L. Szponar, Actual situation in the area of implementing quality assurance systems GMP, GHP and HACCP in Polish food production and processing plants. Food Control, 16(1), 2005, 1-9.

[9] Wisdom Kofi Amoa-Awua, Phyllis Ngunjiri, John Anlobe, Kafui Kpodo, Mary Halm, Alice Ewurafua Hayford, Mogens Jakobsen, The effect of applying GMP and HACCP to traditional food processing at a semi-commercial kenkey production plant in Ghana . Food Control, 18(11), 2007, 1449-1457.

[10] http://en.wikipedia.org/wiki/ISO_22000 